\title{
Deposition of DLC Films onto Oxynitriding-Treated V4E High Vanadium Tool Steel through DC-Pulsed PECVD Process
}

\author{
Shih-Hsien Chang ${ }^{1, *}$, Wei-Chen $\mathrm{Wu}^{1}$, Kuo-Tsung Huang ${ }^{2}$ and Chung-Ming Liu ${ }^{3}$ \\ ${ }^{1}$ Department of Materials and Mineral Resources Engineering, National Taipei University of Technology, \\ Taipei 10608, Taiwan, R. O. China \\ ${ }^{2}$ Department of Auto-Mechanics, National Kangshan Agricultural Industrial Senior High School, Kaohsiung 82049, Taiwan, R. O. China \\ ${ }^{3}$ Department of Chemical and Material Engineering, Lunghwa University of Science and Technology, \\ Taoyuan County 33306, Taiwan, R. O. China
}

In this work, DLC films are prepared by DC-pulsed PECVD after the oxynitriding treatment of V4E high vanadium tool steel. The experimental design includes various power densities $\left(200,400,600\right.$ and $\left.800 \mathrm{~mW} \cdot \mathrm{cm}^{-2}\right)$ with an unbalanced bipolar-pulsed voltage. The deposition time is $90 \mathrm{~min}$, and the $\mathrm{CH}_{4}$ gas flow is maintained at $5 \mathrm{sccm}$, respectively. The experimental results show the duplex coating layers to have better properties when the DLC films are treated by an appropriate power density $\left(400 \mathrm{~mW} \cdot \mathrm{cm}^{-2}\right)$. These films also possess the lowest wear loss volume (for loads of $2 \mathrm{~N}$ and $5 \mathrm{~N}$ of $6.23 \times 10^{-3} \mathrm{~mm}^{3}$ and $1.19 \times 10^{-2} \mathrm{~mm}^{3}$, respectively), the lowest corrosion current $\left(4.09 \times 10^{-4} \mathrm{~A} \cdot \mathrm{cm}^{-2}\right)$ and the highest polarization resistance $\left(258.83 \Omega \cdot \mathrm{cm}^{2}\right)$ after the 3.5 mass $\% \mathrm{NaCl}$ corrosion test. This study confirms that the wear and corrosion resistance of V4E tool steel can be effectively improved through the DLC/oxynitriding duplex treatment. [doi:10.2320/matertrans.M2016375]

(Received October 24, 2016; Accepted February 20, 2017; Published April 25, 2017)

Keywords: DLC, DC-pulsed PECVD, oxynitriding treatment, V4E steel, wear, corrosion

\section{Introduction}

Since the tool steels are used in very different operating environments and conditions, steel must meet a wide variety of requirements, where ultra-high strength with high wear resistance and good toughness is required. To obtain the best steel properties, proper heat treatments including hardening and tempering are required. Currently, numerical methods are increasingly often used in modelling of technological processes. $^{1,2)}$ Vanadis 4 Extra (V4E) tool steel is a Cr-Mo-V alloyed steel which possess the good ductility, high wear resistance and compressive strength, and excellent temper-back resistance. ${ }^{3)}$ Moreover, V4E is especially suitable for applications where adhesive wear and/or chipping are the dominant failure mechanisms. In addition, it also very suitable for blanking and forming of advanced high strength steels. ${ }^{3,4)}$

In order to further extend V4E applications, surface modification is necessary to improve its properties, including corrosion resistance and surface hardness etc. It was reported that nitriding and oxynitriding processes are the widely used surface modification techniques. ${ }^{5)}$ Nitriding is a thermochemical process that is typically used to diffuse nitrogen into ferrous materials. This treatment can improve the surface hardness, fatigue strength, wear and corrosion resistance of nitride components. ${ }^{6,7)}$ The previous studies indicated that oxygen addition can increase the efficiency of gas nitriding, thus the cycle time can be shortened and the energy consumption can be reduced. Oxynitriding processes use air or steam at the end of the nitriding stage, while the complex oxide layer with $\mathrm{Fe}_{2} \mathrm{O}_{3}$ and $\mathrm{Fe}_{3} \mathrm{O}_{4}$ structures are formed on the surface. Actually, better properties including higher surface hardness and better corrosion resistance, can be obtained by oxynitriding than those traditional nitriding, due to the oxides of $\mathrm{Fe}_{3} \mathrm{O}_{4}$ and little $\mathrm{Fe}_{2} \mathrm{O}_{3}$. ${ }^{5,8)}$

Furthermore, diamond-like carbon (DLC) coatings can be

*Corresponding author, E-mail: changsh@ntut.edu.tw used in order to improve the surface properties of steel molds because they combine unique mechanical, tribological and chemical properties. DLC films are metastable amorphous carbon ( $\mathrm{sp}^{3}$ and $\mathrm{sp}^{2}$ bonds) materials with superior tribological characteristics. They have high surface hardness, a low friction coefficient, reduced material adhesion, and they offer high protection against abrasive wear and corrosive attacks. ${ }^{9,10)}$ However, the poor adhesion of DLC films on ferrous alloys reduces a wide range of industrial applications. Because the carbon diffuses into the metals delaying the DLC nucleation. Secondly, the thermal expansion coefficients of the coatings and the steels are not compatible, causing poor adhesion and high residual stresses.9,11) Therefore, many studies of the intermediate layers of DLC coatings have been frequently reported. ${ }^{12,13)}$

On the other hand, a number of different techniques have been used for depositing DLC films such as PVD, RF magnetron sputtering, PECVD, ion beam deposition and cathodic micro-arc discharge. Among them, the most common deposition technique used is plasma-enhanced chemical vapor deposition (PECVD). Moreover, the DC-pulsed PECVD is a novel method, because it is simpler and can be used in industrial scale with lower cost. ${ }^{14-16)}$ As mentioned previously, an oxynitride layer can significantly improve the adhesion and properties of DLC films. Therefore, this research utilized DCpulsed PECVD and DLC/oxynitriding duplex treatments to study the characteristics of DLC films, as well as to increase the tool life of V4E high vanadium tool steel.

\section{Experimental Procedure}

V4E high vanadium tool steel possesses superior mechanical properties, which combine high wear resistance, high toughness and good stability, making it suitable for cold work tools. In the present research, V4E tool steel was chosen as the substrate material to undergo a homogeneous heat treatment: it was quenched at $1100^{\circ} \mathrm{C}$, and tempered at 525 and 
$570^{\circ} \mathrm{C}$ for $2 \mathrm{~h}$, respectively. Hence, the hardness value reached $62 \pm 1$ HRC. Furthermore, a typical microstructure was obtained through the heat treatment, comprising the structure of tempered martensite and various metallic carbides. The chemical compositions (mass $\%$ ) of V4E tool steel are as follows: $4.7 \% \mathrm{Cr}, 3.5 \% \mathrm{Mo}, 3.7 \% \mathrm{~V}, 1.4 \% \mathrm{C}, 0.4 \% \mathrm{Si}, 0.4 \% \mathrm{Mn}$, and $85.9 \% \mathrm{Fe}$. The oxynitriding-treated specimens of $\mathrm{V} 4 \mathrm{E}$ tool steel were nitriding-treated for $8 \mathrm{~h}$ at $550^{\circ} \mathrm{C}$ and oxidized via steam for $60 \mathrm{~min}$ at $525^{\circ} \mathrm{C}$.

In this study, the DC-pulsed PECVD utilized an unbalanced bipolar-pulsed voltage. In order to study the effects of different duty cycles of the bipolar-pulsed PECVD process, the negative-pulsed duty cycle was maintained at $-15 \%+10 \%$, with power densities of $200,400,600$ and $800 \mathrm{~mW} \cdot \mathrm{cm}^{-2}$, respectively. Simultaneously, the coating times of the DCpulsed PECVD was maintained at $90 \mathrm{~min}$; the pulsed voltage and frequency were kept at $-1.5 \mathrm{kV}$ and $10 \mathrm{kHz}$, respectively. Moreover, $\mathrm{CH}_{4}$ gas $(5 \mathrm{sccm})$ was added to the chamber at less than $1.33 \mathrm{~Pa}$ and continued for $90 \mathrm{~min}$, followed by depositing of the DLC films.

Investigation of the properties of DLC films for DLC/ oxynitriding treated V4E tool steel by different power densities of the DC-pulsed PECVD, the Raman spectroscopy analysis (MOF-iHR550), wear test (POD-FM800-25NT), indentation test (Indentec-8150LK), ${ }^{17)}$ scratch test (ASTM C16245, JLST022 Scratch Tester J \& L Tech. Co., Korea) and SEM (Hitachi-S4700) microstructure inspections were performed. The wear resistance of the specimens was evaluated in a ballon-disk test (ASTM G99). The wear test parameters were as follows: the specimen size was $\varnothing 36 \times \mathrm{D} 5 \mathrm{~mm}$, diameter of WC ball (HRA $90 \pm 1$ ) was $6 \mathrm{~mm}$, disk rotation was $200 \mathrm{rpm}$ and total rotation was 10,000 revolutions, axial load was $2 \mathrm{~N}$ and $5 \mathrm{~N}$, and sliding speed of $0.25 \mathrm{~m} \cdot \mathrm{s}^{-1}$, respectively.

Additionally, corrosion potential analysis uses three electrodes method and follows by ASTM G59-97: the reference electrode is a saturated of silver-silver chloride electrode, auxiliary electrode uses a platinum electrode, and the working electrode is connected to the test specimens ${ }^{10,13)}$ The contact area of the specimen was $2.01 \mathrm{~cm}^{2}$. The corrosive solvent used 3.5 mass $\% \mathrm{NaCl}$ was maintained at room temperature. A scanning speed of $0.01 \mathrm{Vs}^{-1}$, initial potential of $-2.0 \mathrm{~V}$, and the final potential of $2.0 \mathrm{~V}$ were controlled. The polarization curve was obtained by Corr-View software to analyze and compare the corrosion potential $\left(\mathrm{E}_{\mathrm{corr}}\right)$, corrosion current $\left(\mathrm{I}_{\text {corr }}\right)$ and polarization resistance $\left(\mathrm{R}_{\mathrm{p}}\right)$ of DLC/oxynitriding-treated V4E specimens.

\section{Results and Discussion}

Figure 1 shows the XRD patterns and surface hardness profile of the oxynitriding-treated V4E tool steel. Significantly, the primary phases and structures of the oxynitride layer were $\mathrm{Fe}_{3} \mathrm{O}_{4}$ and $\mathrm{Fe}_{3} \mathrm{~N}$ ( $\varepsilon$ phase), as shown in Fig. 1(a). While $\alpha$-Fe was the main element of the matrix for the V4E tool steel, it also appeared in the XRD patterns. In this study, neither a hard, brittle nor dense structure of the $\delta-\mathrm{Fe}_{2} \mathrm{~N}$ phase was found. It was speculated that the wear properties would be significantly improved in the subsequent wear tests. Moreover, a complex oxide layer of $\mathrm{Fe}_{3} \mathrm{O}_{4}$ and $\mathrm{Fe}_{3} \mathrm{~N}$ structures was successfully formed on the surface. In fact, the oxynitride
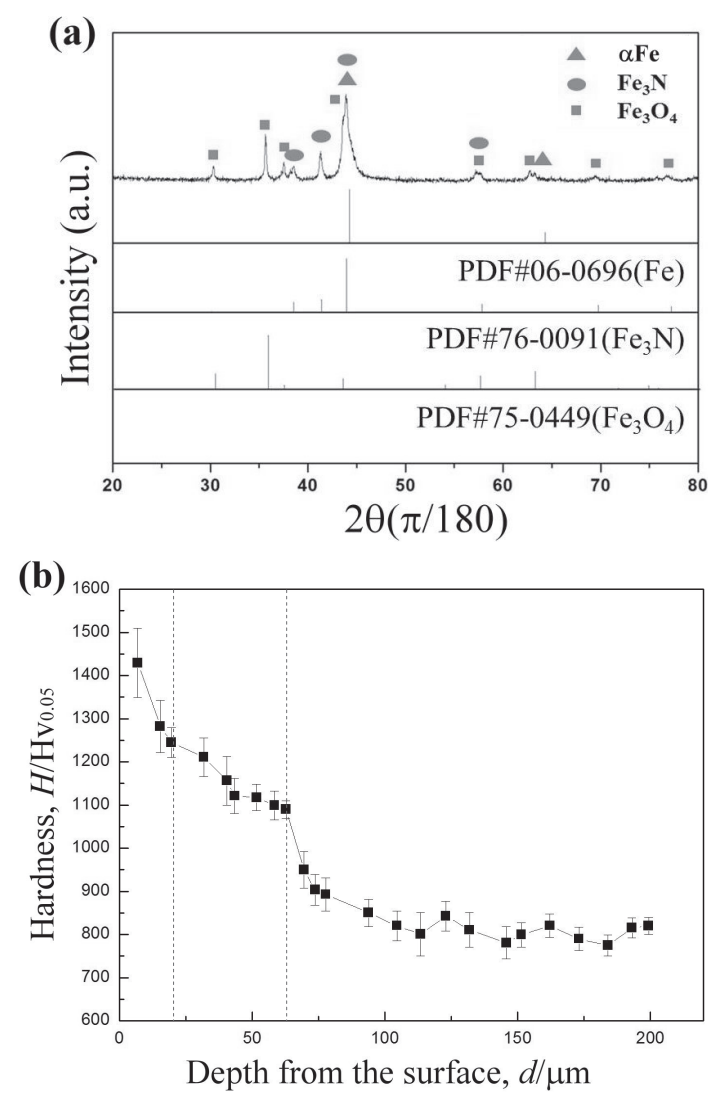

Fig. 1 XRD patterns and hardness test results of the oxynitriding treated V4E specimens.

layer not only improved the wear and corrosion resistance, but, as the intermediate layer, it was advantageous to the adhesive strength. This result confirmed that the V4E tool steel was successfully nitride-treated at $550^{\circ} \mathrm{C}$ for $8 \mathrm{~h}$ and oxide-treated at $525^{\circ} \mathrm{C}$ for $60 \mathrm{~min}$, and possessed a well-oxidized layer and stable crystal structures.

The surface hardness was measured at an applied load of $0.49 \mathrm{~N}$ (approximately equal to $50 \mathrm{~g}$, expressed as $\mathrm{HV}_{0.05}$ in this study, and tested at least three times) along the cross section of the test pieces through the micro-hardness tester (VMT-XT). As a result, the depth profile of the micro-hardness of the oxynitriding-treated V4E tool steel was obtained, as shown in Fig. 1(b). In addition, owing to the oxynitriding treatment, the specimen's surface generated several types of nitrides and oxides. When the specimen's surface possessed a higher concentration of oxide and nitrogen ions, a significant hardening effect of the atomic lattice resulted. As a result, the surface hardness of the oxynitriding-treated specimen was elevated to a high of $\mathrm{HV}_{0.05} 1429$. When the depth of the hardened layer was less than $20 \mu \mathrm{m}$, the hardness value was more than $\mathrm{HV}_{0.05}$ 1200. Moreover, when the depth of the diffusion layer was $20-70 \mu \mathrm{m}$, the hardness value was about $\mathrm{HV}_{0.05}$ 900-1100. However, with an increase in the diffusion depth, the oxide and nitrogen concentrations were obviously reduced, which led to a decrease in hardness. The hardness reverted to the original hardness of the substrate (about $\mathrm{HV}_{0.05}$ 772.5) after a depth of $70 \mu \mathrm{m}$, as seen in Fig. 1(b). Clearly, stable oxide $\left(\mathrm{Fe}_{3} \mathrm{O}_{4}\right)$ and nitride layers $\left(\mathrm{Fe}_{3} \mathrm{~N}\right)$ were successfully formed on the surface of the V4E tool steel by the oxynitriding treatments, which led to an increase in the surface 
hardness of the specimen.

Figure 2 shows the SEM cross-sectional observations of the DLC films for the different power densities of the DCpulsed PECVD. Significantly, the DLC films possessed a mixed diamond $\left(\mathrm{sp}^{3}\right)$ and graphite $\left(\mathrm{sp}^{2}\right)$ amorphous structure. Furthermore, the thickness of the DLC films displayed a similar level after each of the different power densities of the DC-pulsed PECVD treatments of about $2.8 \mu \mathrm{m}$. Apparently, the thickness of the DLC films was not affected by the power density. The adhesion layer between the steel substrate and the DLC thin films is usually referred to as the interlayer or intermediate layer. Previous literature ${ }^{11)}$ showing the cross-section images of DLC/interlayer/substrate systems give no evidence as to the existence and/or function of the two interfaces that constitute the interlayer. In this work, the intermediate layer of the V4E steel and the DLC films was the oxynitride layer. As shown in Figs. 2(a)-2(d), the DLC films possessed good adhesion, while the SEM images showed no micro-cracks in the DLC films (Fig. 2). Clearly, the oxynitride layer had a significant effect on the adhesion of DLC films.

Previous literature has shown that the mechanical properties of DLC films are strongly affected by the hydrogen content, because hydrogen is monovalent and it acts to terminate potential carbon-carbon bonds. ${ }^{18)}$ Moreover, other literature has indicated that a larger supply of hydrocarbon in the plasma contributes to film growth. The DLC films' hydrogenation presented few variations when each system was analyzed separately. ${ }^{19)}$ In this study, the thickness of the DLC films displayed a similar level after each of the different power densities of DC-pulsed PECVD treatments. It is reasonable to suggest that the hydrogen content of the specimens would show insignificant variations. An important potential benefit is that carbon clusters play a significant role in the growth of DLC films or crystalline diamond. In general, Gaussian function dismantling and synthesis are used to calculate the results of the integration area ratio $\left(\mathrm{I}_{\mathrm{D}} / \mathrm{I}_{\mathrm{G}}\right)$ and the offset of the $\mathrm{G}$-peak for the different power densities of DC-pulsed PECVD. The previous literature have indicated that a relationship between the G-peak position, $\mathrm{I}_{\mathrm{D}} / \mathrm{I}_{\mathrm{G}}$, and $\mathrm{sp}^{3}$ content. ${ }^{20)}$ The Raman spectrum of graphitic carbon consists of two peak: the $G$ peak
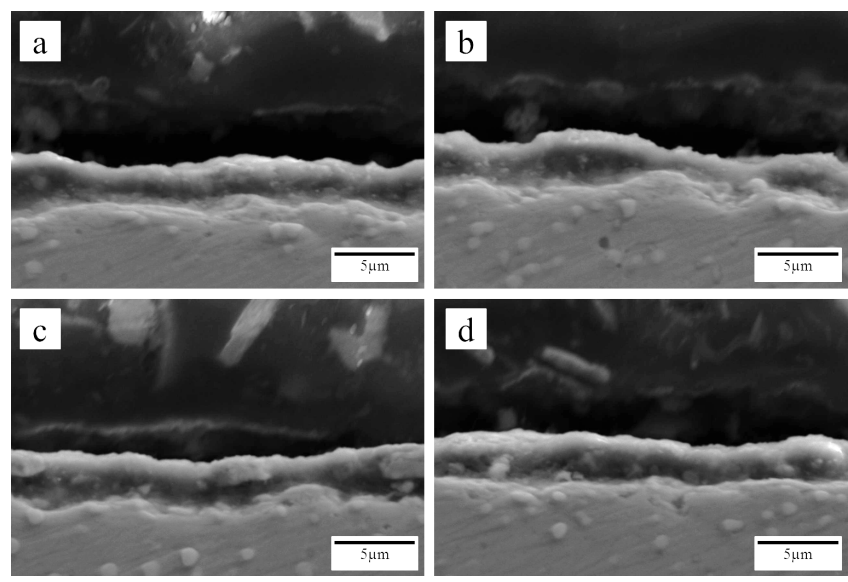

Fig. 2 SEM cross-sectional observations of the DLC films by the different power densities of DC-pulsed PECVD: (a) 200, (b) 400, (c) 600, and (d) $800 \mathrm{~mW} \cdot \mathrm{cm}^{-2}$. centered on $1550 \mathrm{~cm}^{-1}$ is the zone center $E_{2 \mathrm{~g}}$ mode of the perfect graphite crystal and the D peak centered on $1350 \mathrm{~cm}^{-1}$ is a zone edge $A_{1 g}$ mode which is activated by disorder. The $\mathrm{D}$ mode is a common feature of all disordered graphitic carbons whose intensity related to the $G$ peak has been shown to vary inversely with the size of the graphite crystallites. ${ }^{21,22)}$ The $\mathrm{I}_{\mathrm{D}} / \mathrm{I}_{\mathrm{G}}$ ratio is often used to derive an $\mathrm{sp}^{2}$ correlation length for a-C(:H). Both $\mathrm{I}_{\mathrm{D}} / \mathrm{I}_{\mathrm{G}}$ and the optical gap depend on $\mathrm{L}_{\mathrm{a}}$, and according to the following equation ${ }^{21)}$ :

$$
\mathrm{I}_{\mathrm{D}} / \mathrm{I}_{\mathrm{G}}=\mathrm{k} / \mathrm{L}_{\mathrm{a}}
$$

Where $\mathrm{k}$ depends on factors such as the electrode areas, and $\mathrm{L}_{\mathrm{a}}$ is the length of $\mathrm{a}-\mathrm{C}(: \mathrm{H})$. It suggested that the $\mathrm{I}_{\mathrm{D}} / \mathrm{I}_{\mathrm{G}}$ increased with increasing bias voltage for plasma-deposited $\mathrm{a}-\mathrm{C}: \mathrm{H}$, implying that $\mathrm{L}_{\mathrm{a}}$ falls with increasing bias from above equation. In this study, we seriously consider the evolution of G-peak position and $\mathrm{I}_{\mathrm{D}} / \mathrm{I}_{\mathrm{G}}$ ratio. The offset of the G-peak can also reveal the relative performance of the carbon films. For all specimens, a bulge in the Raman band occurred at $1550 \mathrm{~cm}^{-1}$, as shown in Fig. 3(a). However, the main difference was not apparent. It was necessary to further analyze the synthesized peak decomposition to obtain the value of $\mathrm{I}_{\mathrm{D}} / \mathrm{I}_{\mathrm{G}}$ and the offset of the G-peak position.

Figure 3(b) shows that at the power density of $200 \mathrm{~mW} \cdot \mathrm{cm}^{-2}$ the highest $\mathrm{I}_{\mathrm{D}} / \mathrm{I}_{\mathrm{G}}$ value $(0.95)$ and the smallest offset amount of G-peak $\left(1563 \mathrm{~cm}^{-1}\right)$ were obtained. Upon increasing the power density $\left(200 \rightarrow 400 \rightarrow 600 \rightarrow 800 \mathrm{~mW} \cdot \mathrm{cm}^{-2}\right)$ of the DC-pulsed PECVD, both the $\mathrm{I}_{\mathrm{D}} / \mathrm{I}_{\mathrm{G}}$ value and the position of the G-peak showed an obvious decline, and then rapidly rose, respectively. Based on the relationship between $\mathrm{I}_{\mathrm{D}} / \mathrm{I}_{\mathrm{G}}$ and the size of the graphite planes, values of $\mathrm{I}_{\mathrm{D}} / \mathrm{I}_{\mathrm{G}}$ greater than unity
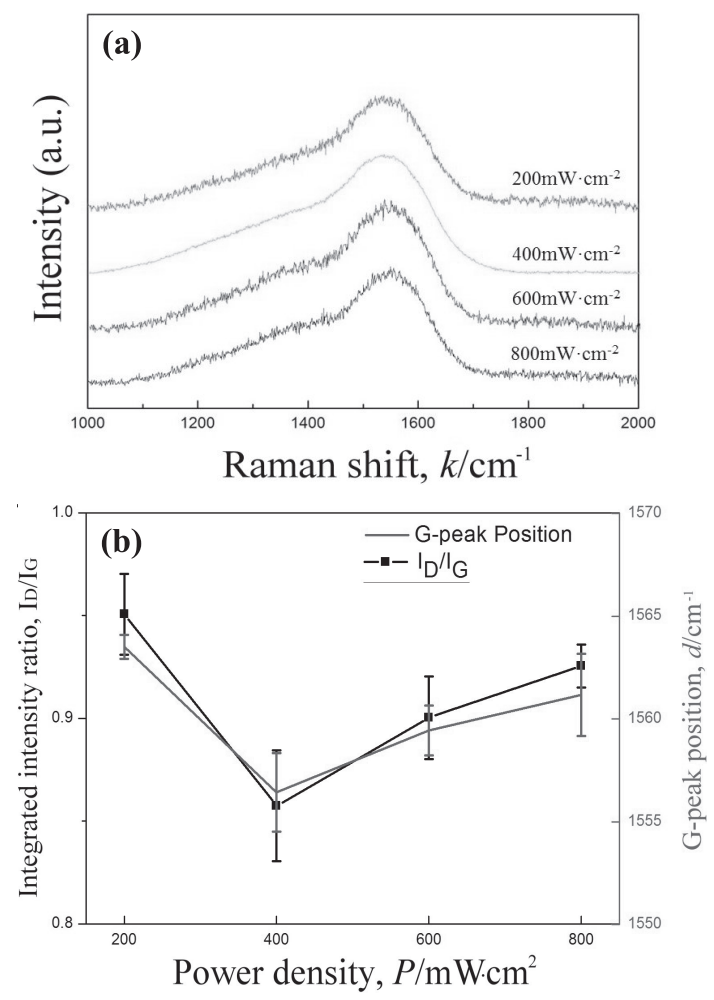

Fig. 3 Comparison of the (a) original Raman spectrum, and (b) $\mathrm{I}_{\mathrm{D}} / \mathrm{I}_{\mathrm{G}}$ and G-peak of Raman analysis by the different power densities of DC-pulsed PECVD. 
are often found in a-C and a-C:H. The presence of a large D component suggests that the $\mathrm{sp}^{2}$ cluster model is basically correct. $^{21)}$ It is reasonable to suggest that increasing the $\mathrm{I}_{\mathrm{D}} / \mathrm{I}_{\mathrm{G}}$ value resulted in the size of the graphite planes decreased. Thus, as shown in Fig. 3(b), it is possible to say that increasing the power density from 200 to $400 \mathrm{Wcm}^{-1}$ (the $\mathrm{I}_{\mathrm{D}} / \mathrm{I}_{\mathrm{G}}$ value decline), the size of the graphite planes increases. However, increasing the power density from 400 to $800 \mathrm{Wcm}^{-1}$ (the $\mathrm{I}_{\mathrm{D}} / \mathrm{I}_{\mathrm{G}}$ value rose), the size of the graphite planes decreases. In addition, the $400 \mathrm{~mW} \cdot \mathrm{cm}^{-2}$ specimen had the lowest $I_{D} / I_{G}$ value (0.86) and a relatively greater offset amount of the G-peak $\left(1556 \mathrm{~cm}^{-1}\right)$. In the present research, the power density of $200 \mathrm{~mW} \cdot \mathrm{cm}^{-2}$ of the DLC film had a relatively lower plasma energy, which likely resulted in the greater $\mathrm{sp}^{2}$ bond and the higher $\mathrm{I}_{\mathrm{D}} / \mathrm{I}_{\mathrm{G}}$ value. As the power density increased $\left(200 \rightarrow 400 \mathrm{~mW} \cdot \mathrm{cm}^{-2}\right)$, the plasma bombardment energy was obviously enhanced, which easily allowed for the $\mathrm{sp}^{2}$ to transform to an $\mathrm{sp}^{3}$ bond. The experimental results showed that the $400 \mathrm{~mW} \cdot \mathrm{cm}^{-2}$ specimen produced more stable $\mathrm{sp}^{3}$ bonds $\left(\mathrm{I}_{\mathrm{D}} /\right.$ $\mathrm{I}_{\mathrm{G}}$ of 0.86 and $\mathrm{G}$-peak offset of $1556 \mathrm{~cm}^{-1}$ ), with presumably better mechanical properties.

Our previous study ${ }^{3)}$ also showed 250 and $300 \mathrm{~mW} \cdot \mathrm{cm}^{-2}$ to have more off-time, sufficient to release the charge accumulation; thus, the power density of the energy and the gas dissociation rate were relatively lower, which resulted in the poor properties of the DLC films. Conversely, the higher ion energy of the plasma bombardment (over $600 \mathrm{~mW} \cdot \mathrm{cm}^{-2}$ ) easily caused the high increase in the specimen's surface energy and, thus, the generation of unstable structures. This led to the likelihood of the $\mathrm{sp}^{3}$ structure of the DLC films transforming to $\mathrm{sp}^{2}$ and further affecting the film's characteristics, so that the DLC films gradually approached graphitization. Consequently, the 600 and $800 \mathrm{~mW} \cdot \mathrm{cm}^{-2}$ specimens possessed a relatively higher value of $\mathrm{I}_{\mathrm{D}} / \mathrm{I}_{\mathrm{G}}$ and smaller G-peak offset (compared to the $400 \mathrm{~mW} \cdot \mathrm{cm}^{-2}$ specimen).

Figure 4 shows the SEM images of the loading impact tests (Rockwell C scale indentation) for various power densities of the DC-pulsed PECVD process. All specimens had similar surface features after the loading impact test. There were radial cracks on the substrate, but no significant peeling-off phenomenon was generated, as seen in Figs. 4(a)-4(d). The DLC coatings for the 200 and $800 \mathrm{~mW} \cdot \mathrm{cm}^{-2}$ power densities
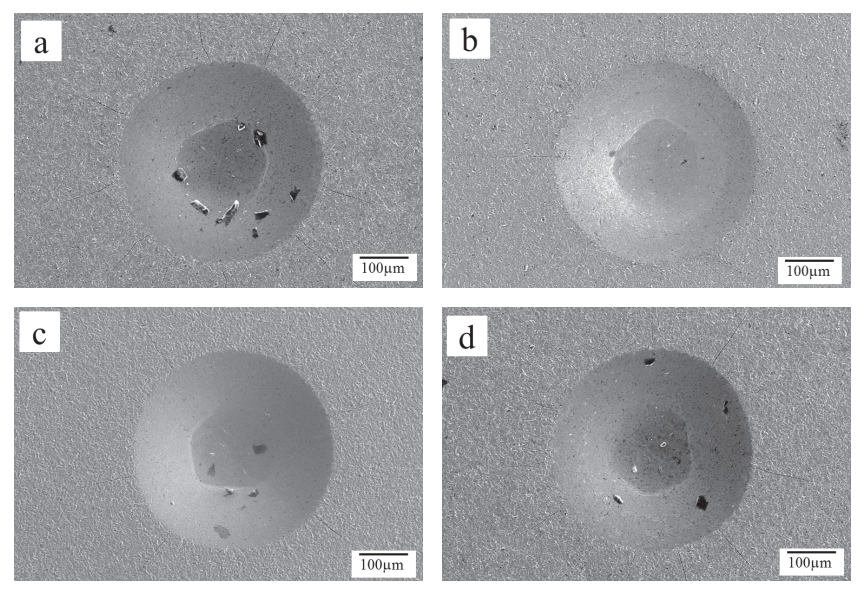

Fig. 4 SEM images of the loading impact test by the different power densities of DC-pulsed PECVD: (a) 200, (b) 400, (c) 600, and (d) $800 \mathrm{~mW} \cdot \mathrm{cm}^{-2}$. evidenced more obvious radial cracks, as shown in Figs. 4(a) and 4(d). Actually, the radial cracks did not result from fractures of the DLC films, but were caused by the compressive stress on the specimen's surface from the oxynitriding process. Generally speaking, the adhesion strength of DLC films on steel is poor ${ }^{10)}$ and adhesion-enhancing materials have been used directly as intermediate layers. In this work, the oxynitriding process used pre-treated V4E tool steel as an intermediate layer. The nitrogen and oxide atoms entered the interstices of the lattice via atomic diffusion, and easily resulted in the lattice deformation and surface hardening. Furthermore, the lower plasma bombardment $\left(200 \mathrm{~mW} \cdot \mathrm{cm}^{-2}\right)$ readily produced the loose $\mathrm{sp}^{2}$ bond, while the higher plasma bombardment $\left(800 \mathrm{~mW} \cdot \mathrm{cm}^{-2}\right)$ led to greater internal stress and more uneven $\mathrm{sp}^{3}$ and $\mathrm{sp}^{2}$ structures. The VDI 3198 indentation test ${ }^{17)}$ showed the adhesion strength of the power densities of 400 and $600 \mathrm{~mW} \cdot \mathrm{cm}^{-2}$ DLC film treatments to be the HF 1 grade and the 200 and $800 \mathrm{~mW} \cdot \mathrm{cm}^{-2}$ the $\mathrm{HF} 1 \sim 2$ grade.

Figure 5 shows the surface morphology observations of the scratch tests after the different power densities of the DCpulsed PECVD process. For the scratch test, the load was gradually increased from 0 to $100 \mathrm{~N}$, and the total traveling distance was $5 \mathrm{~mm}$. All specimens showed no significant ruptures on the DLC films after the scratch tests. Even at a maximum load of $100 \mathrm{~N}$, a good bonding strength of the DLC films was retained. Significantly, all specimens were better able to resist rupture and the adhesion strength of the DLC films remained fairly stable. The poor adhesion of DLC films on ferrous alloys limits the range of industrial applications. ${ }^{11)}$ Interlayers are commonly employed in an attempt to improve DLC adhesion on metallic alloys. In these experiments, with the oxynitride layer as an interlayer between the DLC films and V4E tool steel, the adhesion strength of DLC films was effectively improved. Further observation of the specimens' appearance after the scratch tests (as seen in Figs. 5(a)-5(d)) confirmed that all specimens possessed good DLC coating adhesion as a result of the good interlayer. This result also agreed with our finding in the foregoing indentation test result (Fig. 4).

As already noted, DLC films possess superior tribological characteristics correlated to the fraction of $\mathrm{sp}^{3}$ bonds in the films, such as a low friction coefficient and high wear resistance. Generally, the volume loss of the wear tests allows the wear rate of the material to be calculated. Figure 6 shows the

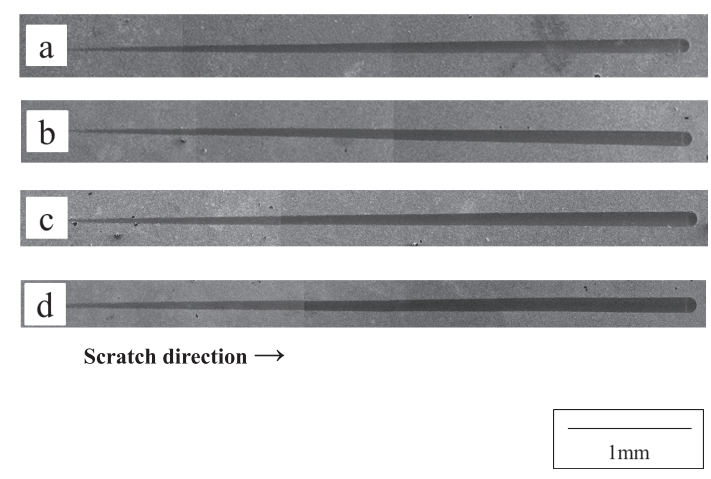

Fig. 5 Surface morphology observations of scratch test by the different power densities of DC-pulsed PECVD: (a) 200, (b) 400, (c) 600, and (d) $800 \mathrm{~mW} \cdot \mathrm{cm}^{-2}$ 
wear loss volume and specific wear rate for the different power densities of the DC-pulsed PECVD. Figure 6(a) reveals that the wear loss volume showed an obvious decrease and then an increase as the power density was enhanced. The highest wear volume value $\left(1.72 \times 10^{-2} \mathrm{~mm}^{3}\right)$ occurred at the power density of $200 \mathrm{~mW} \cdot \mathrm{cm}^{-2}$ after the lower load $(2 \mathrm{~N})$ of the wear tests. The DLC films at a power density of $200 \mathrm{~mW} \cdot \mathrm{cm}^{-2}$ exhibited an unstable $\mathrm{sp}^{3} / \mathrm{sp}^{2}$ structure, which showed in the wear test results. The lowest wear loss volume $\left(6.23 \times 10^{-3} \mathrm{~mm}^{3}\right)$ occurred at a power density of $400 \mathrm{~mW} \cdot \mathrm{cm}^{-2}(2 \mathrm{~N})$. As the axial load increased $(2 \rightarrow 5 \mathrm{~N})$, the wear loss volume of all specimens at the different power densities dramatically increased, as also shown in Fig. 6(a). The lowest wear loss volume $\left(1.21 \times 10^{-2} \mathrm{~mm}^{3}\right)$ occurred at the power density of $400 \mathrm{~mW} \cdot \mathrm{cm}^{-2}$ at a higher load $(5 \mathrm{~N})$, while the highest value of wear loss volume $\left(2.27 \times 10^{-2} \mathrm{~mm}^{3}\right)$ was at a power density of $200 \mathrm{~mW} \cdot \mathrm{cm}^{-2}$ after the wear test $(5 \mathrm{~N})$. Clearly, the $400 \mathrm{~mW} \cdot \mathrm{cm}^{-2}$ specimen possessed the optimal wear resistance under the different loads of the wear tests.

The specific wear rate is defined as the wear volume loss per unit distance per unit load. In this research, all the specific wear rates under a high axial load $(5 \mathrm{~N})$ were lower than that for under a low axial load $(2 \mathrm{~N})$ for the different power densities, as shown in Fig. 6(b). The previous literature showed that higher thermal energy caused the DLC structure to be transformed into the graphite structure. ${ }^{23)}$ In this study, the specimen's surface generated a higher energy under a high axial load of the wear process, which easily resulted in the
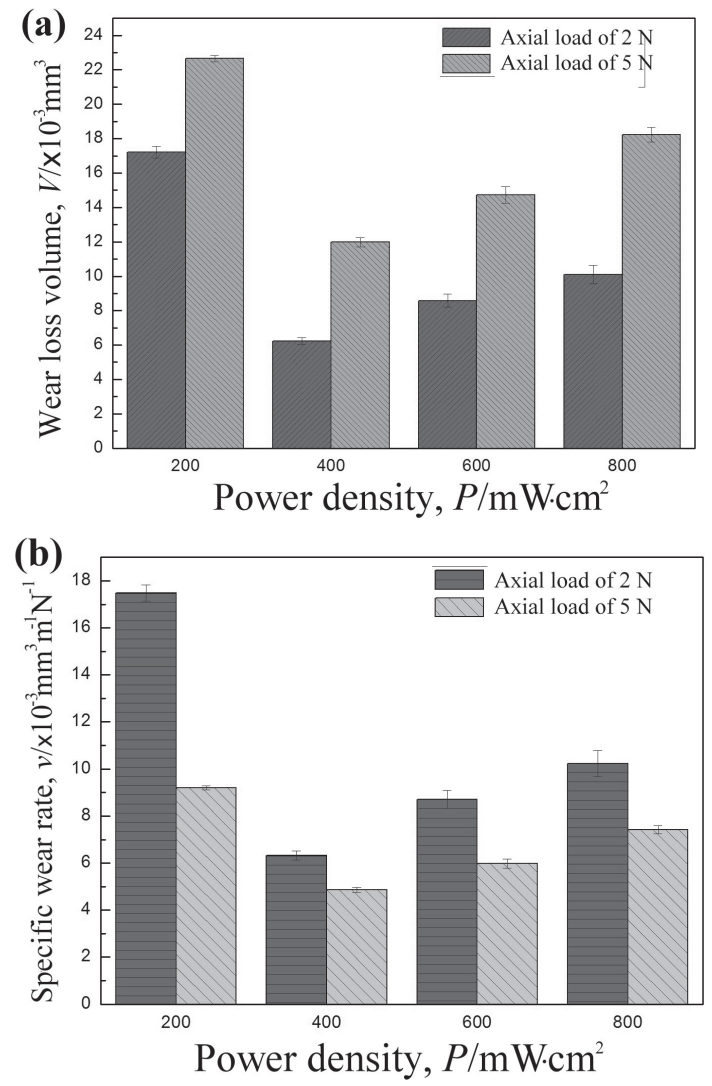

Fig. 6 Comparison of the wear volume loss of various wear tests by the different power densities of DC-pulsed PECVD: (a) load $2 \mathrm{~N}$, and (b) load $5 \mathrm{~N}$ and sliding speed $0.25 \mathrm{~m} \cdot \mathrm{s}^{-1}$, respectively. graphitization phenomenon of the DLC film, and caused the $\mathrm{sp}^{3}$ transform to a $\mathrm{sp}^{2}$ bond. As a result, the wear resistance was obviously improved by the self-lubricating effect of the graphite. In other words, the high axial load specimens possessed a relatively lower specific wear rate. Besides, the specific wear rate generated a significant declining trend under a high axial load wear process. This result confirmed the relationship between the high energy and graphitization phenomenon of the DLC films. The lowest specific wear rate of $4.86 \times 10^{-3} \mathrm{~mm}^{3} \mathrm{~m}^{-1} \cdot \mathrm{N}^{-1}(5 \mathrm{~N})$ appeared at a power density of $400 \mathrm{~mW} \cdot \mathrm{cm}^{-2}$. Conversely, the highest specific wear rate of $1.75 \times 10^{-2}(2 \mathrm{~N}) \mathrm{mm}^{3} \mathrm{~m}^{-1} \cdot \mathrm{N}^{-1}$ appeared at a power density of $200 \mathrm{~mW} \cdot \mathrm{cm}^{-2}$. According to the above discussion and results, we were able to confirm that at a power density of $400 \mathrm{~mW} \cdot \mathrm{cm}^{-2}$ the DC-pulsed PECVD resulted in DLC films with the ideal adhesion strength and optimal wear resistance.

Figure 7 shows the SEM surface morphology of the wear test under a load of $5 \mathrm{~N}$ and a sliding speed of $0.25 \mathrm{~m} \cdot \mathrm{s}^{-1}$ for the different power densities of the DC-pulsed PECVD. Figures 7(a) and 7(d) reveal the relatively wide and deep wear tracks, while Figs. 7(b) and 7(c) show a significantly shallower wear track. Particularly, the surface morphology showed almost no abrasion damage at a power density of $400 \mathrm{~mW} \cdot \mathrm{cm}^{-2}$, as shown in Fig. 7(b). In addition, the power density of $600 \mathrm{~mW} \cdot \mathrm{cm}^{-2}$ generated a slight spalling phenomenon between the DLC films and the V4E substrate and displayed a wide but shallow wear track, as shown in Fig. 7(c). Conversely, the DLC films produced a dramatic peeling phenomenon and micro-cracks after the lowest and highest power densities of 200 and $800 \mathrm{~mW} \cdot \mathrm{cm}^{-2}$, as shown in Figs. 7(a) and 7(d). As mentioned, too-low and too-high power densities usually generated an unstable plasma energy, which easily caused a low content of both $\mathrm{sp}^{3}$ carbon and hydrogen under a plasma atmosphere. Therefore, it was reasonable to suggest that the power densities of 400 and $600 \mathrm{~mW} \cdot \mathrm{cm}^{-2}$ with more $\mathrm{sp}^{3}$ bonding and a stable DLC structure resulted in good adhesion strength and wear resistance. This also agreed with our previous finding.

Generally speaking, DLC films have many excellent properties, such as high hardness, low friction coefficient and high corrosion resistance; thus, the corrosion behavior of the DLC
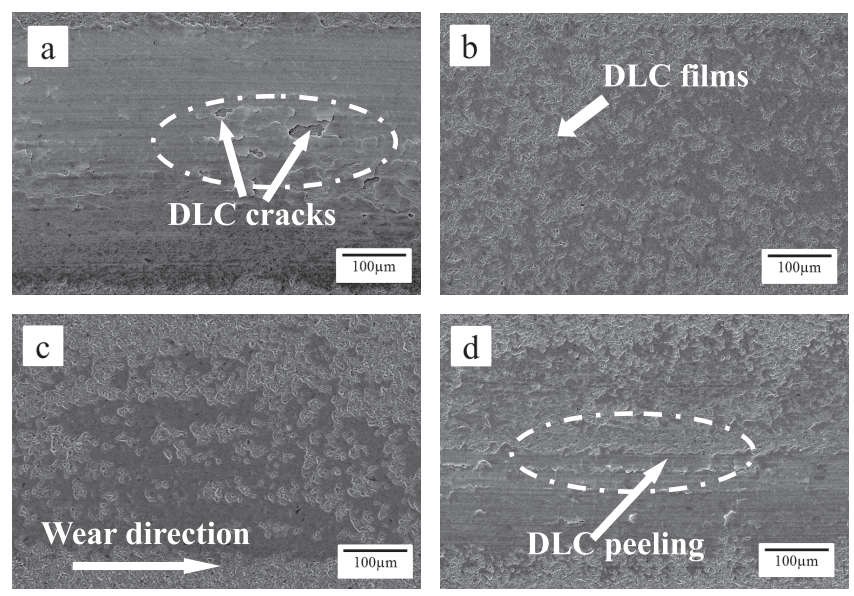

Fig. 7 Surface morphology of wear test (sliding speed of $0.25 \mathrm{~m} \cdot \mathrm{s}^{-1}$ and load of $5 \mathrm{~N}$ ) by the different power densities of DC-pulsed PECVD: (a) 200, (b) 400, (c) 600, and (d) $800 \mathrm{~mW} \cdot \mathrm{cm}^{-2}$. 
films was an important consideration. Figure 8 shows the Tafel slope results of the V4E specimens for the various power densities of the DC-pulsed PECVD after the 3.5 mass\% $\mathrm{NaCl}$ corrosion test. All specimens possessed a significant passivation phenomenon. The passivation layer generated a protective effect. A comparison of the corrosion resistance for the different power densities of the DLC/oxynitriding-treated V4E specimens is shown in Table 1. The samples with a lower current density $\left(\mathrm{I}_{\mathrm{corr}}\right)$ and higher potential $\left(\mathrm{E}_{\mathrm{corr}}\right.$ or polarization resistance $\mathrm{R}_{\mathrm{p}}$ ) evidenced better corrosion resistance. ${ }^{10)}$ Table 1 lists the corrosion resistance $\left(\mathrm{I}_{\text {corr }}, \mathrm{E}_{\mathrm{corr}}\right.$ and $\left.\mathrm{R}_{\mathrm{p}}\right)$ of the different power densities of the DLC/oxynitriding-treated $\mathrm{V} 4 \mathrm{E}$ specimens. The lowest corrosion current $(4.09 \times$ $10^{-4} \mathrm{~A} \cdot \mathrm{cm}^{-2}$ ) and highest polarization resistance $\left(258.83 \Omega \cdot \mathrm{cm}^{2}\right)$ of the V4E specimens appeared at a power density of $400 \mathrm{~mW} \cdot \mathrm{cm}^{-2}$, while the $200 \mathrm{~mW} \cdot \mathrm{cm}^{-2}$ specimen possessed the highest corrosion current $\left(6.96 \times 10^{-4} \mathrm{~A} \cdot \mathrm{cm}^{-2}\right)$ and the lowest polarization resistance $\left(192.54 \Omega \cdot \mathrm{cm}^{2}\right)$. This result indicated that the $400 \mathrm{~mW} \cdot \mathrm{cm}^{-2}$ specimen had a relatively stable $\mathrm{sp}^{3} / \mathrm{sp}^{2}$ bonding structure, which helped for improving the corrosion resistance. However, increases in the power density led to increases in the residual stress and loose structures $\left(\mathrm{sp}^{2}\right)$. As the power density increased $(400 \rightarrow$ $\left.600 \rightarrow 800 \mathrm{~mW} \cdot \mathrm{cm}^{-2}\right)$, the corrosion current increased $\left(4.09 \rightarrow 5.99 \rightarrow 6.37 \mathrm{~A} \cdot \mathrm{cm}^{-2}\right)$ and the polarization resistance declined slightly $\left(258.83 \rightarrow 239.08 \rightarrow 223.1 \Omega \cdot \mathrm{cm}^{2}\right)$, respectively.

Although the DLC films possessed excellent chemical inertness, the $\mathrm{sp}^{2}$ bonding generally accelerated the electro-migration between the substrate and etching solutions, which resulted in the increased current density and reduced corrosion resistance. Only with more stable $\mathrm{sp}^{3}$ bonding structures

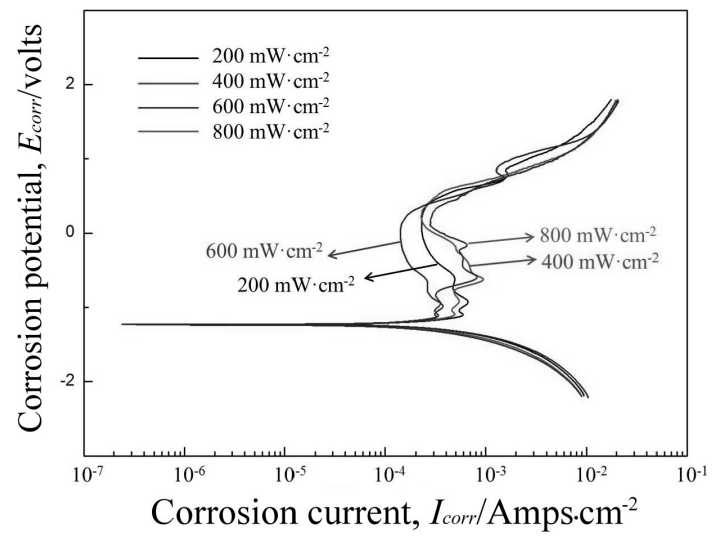

Fig. 8 Tafel results of V4E specimens by the different power densities of DC-pulsed PECVD after 3.5 mass\% NaCl corrosion test.

Table 1 Comparison of the corrosion resistance of V4E specimens by the different power densities of DC-pulsed PECVD after 3.5 mass $\% \mathrm{NaCl}$ corrosion test.

\begin{tabular}{cccc}
\hline Specimens $\left(\mathrm{mW} \cdot \mathrm{cm}^{-2}\right)$ & $\mathrm{I}_{\text {corr }}\left(\times 10^{-4} \mathrm{~A} \cdot \mathrm{cm}^{-2}\right)$ & $\mathrm{E}_{\text {corr }}($ Volts $)$ & $\mathrm{R}_{\mathrm{p}}\left(\Omega \cdot \mathrm{cm}^{2}\right)$ \\
\hline 200 & 6.96 & -1.03 & 192.54 \\
400 & 4.09 & -1.00 & 258.83 \\
600 & 5.99 & -1.02 & 239.08 \\
800 & 6.37 & -1.03 & 223.10 \\
\hline
\end{tabular}

could the DLC films possess good corrosion resistance. Moreover, oxidation-treated steel usually forms a passive film ( $\mathrm{Fe}_{3} \mathrm{O}_{4}$ structures), which contributes to a better anti-corrosion property during the corrosion test. Therefore, the stable DLC structures and oxide layers of the DLC/oxynitrided films were essential to improve the corrosion resistance. Consequently, the $400 \mathrm{~mW} \cdot \mathrm{cm}^{-2}$ specimen of the DC-pulsed PECVD possessed the optimal corrosion resistance in a 3.5 mass $\% \mathrm{NaCl}$ solution.

\section{Conclusions}

The experimental results showed that DLC thin films (about $2.8 \mu \mathrm{m}$ ) were successfully obtained after V4E tool steel was treated using the DLC/oxynitriding duplex treatment. In this work, the optimal power density of the DCpulsed PECVD for V4E tool steel was $400 \mathrm{~mW} \cdot \mathrm{cm}^{-2}$. Moreover, the increase in the plasma bombardment energy resulted from the increased power density. The excess plasma bombardment energy appeared at 600 and $800 \mathrm{~mW} \cdot \mathrm{cm}^{-2}$, which easily caused the likelihood of the $\mathrm{sp}^{3}$ to convert to $\mathrm{sp}^{2}$ bonds and the $\mathrm{I}_{\mathrm{D}} / \mathrm{I}_{\mathrm{G}}$ values was increased. As the $400 \mathrm{~mW} \cdot \mathrm{cm}^{-2}$ specimen produced the more stable $\mathrm{sp}^{3} / \mathrm{sp}^{2}$ bonds and had better adhesion strength due to the suitable power density, it possessed the lowest $\mathrm{I}_{\mathrm{D}} / \mathrm{I}_{\mathrm{G}}(0.86)$ and the greatest offset of the G-peak $\left(1556 \mathrm{~cm}^{-1}\right)$.

In addition, the lowest wear loss volume of $6.23 \times 10^{-3} \mathrm{~mm}^{3}$ (load of $2 \mathrm{~N}$ ) occurred at a power density of $400 \mathrm{~mW} \cdot \mathrm{cm}^{-2}$, which also accounted for the lowest specific wear rate of $4.86 \times 10^{-3} \mathrm{~mm}^{3} \mathrm{~m}^{-1} \cdot \mathrm{N}^{-1}$ (load of $5 \mathrm{~N}$ ). This specimen also had a relatively low corrosion current $\left(4.09 \times 10^{-4} \mathrm{~A} \cdot \mathrm{cm}^{-2}\right)$ and high polarization resistance $\left(258.83 \Omega \cdot \mathrm{cm}^{2}\right)$. Clearly, the power density of $400 \mathrm{~mW} \cdot \mathrm{cm}^{-2}$ specimens possess the stable $\mathrm{sp}^{3} / \mathrm{sp}^{2}$ bonding, better properties, as well as good adhesion strength and wear resistance. Consequently, this study confirmed that these ideal DLC films were effective in improving the tribological and corrosion properties of the DLC/oxynitriding-treated V4E tool steel.

\section{Acknowledgments}

This research is supported by the ASSAB STEELS TAIWAN CO., LTD and Lunghwa University of Science and Technology. The authors would like to express their appreciations for Dr. Harvard Chen, Mr. Michael Liao, Prof. Jeoulong Lee, and Mr. Meng-Yu Liu.

\section{REFERENCES}

1) T. Domański and A. Bokota: Int. J. Mech. Sci. 96-97 (2015) 47-57.

2) H.G. Nanesa and M. Jahazi: Mater. Sci. Eng. A 634 (2015) 32-36.

3) "VANADIS 4 EXTRA SuperClean". ASSAB Steel Website. http:// www.assab.com/media/ASSAB-Vanadis4ExtraSuperClean.pdf, (accessed 2016-07-26)

4) “Uddeholm Vanadis ${ }^{\circledR} 4$ Extra SuperClean”. Uddeholm Steel Website. http://www.uddeholm.com/files/PB_Uddeholm_vanadis_4_extra_ english.pdf, (accessed 2016-07-26)

5) H. Liu, J.C. Li, Y.T. Chai, W. Wei and J. Hu: Vac. 121 (2015) 18-21.

6) A. Alsaran, H. Altun, M. Karakan and A. Çelik: Surf. Coat. Technol. 176 (2004)344-348

7) S. Kikuchi, T. Fukuoka, T. Sasaki, J. Komotori, K. Fukazawa, Y. Misaka and K. Kawasaki: Mater. Trans. 54 (2013) 344-349. 
8) S.H. Chang, T.P. Tang, Y.C. Chen and J.K. Chen: ISIJ Int. 49 (2009) 421-424.

9) E.L. Dalibon, V. Trava-Airoldi, L.A. Pereira, A. Cabo and S.P. Brühl: Surf. Coat. Tech. 255 (2014) 22-27.

10) S.H. Chang, C.C. Yu, K.T. Huang and C.M. Liu: ISIJ Int. 55 (2015) 2631-2638.

11) F. Cemin, C.D. Boeira and C.A. Figueroa: Tribol. Int. 94 (2016) 464 469.

12) Z.Y. Xu, H. Sun, Y.X. Leng, X.Y. Li, W.M. Yang and N. Huang: Appl. Surf. Sci. 328 (2015) 319-324.

13) S.H. Chang, Y.K. Lin and K.T. Huang: Surf. Coat. Tech. 207 (2012) 571-578.

14) M. Ebrahimi, F. Mahboubi and M.R. Naimi-Jamal: Diamond Related Materials 52 (2015) 32-37.

15) G. Capote, E.J. Corat and V.J. Trava-Airoldi: Surf. Coat. Tech. 260
(2014) 133-138

16) T. Morita, K. Andatsu, S. Hirota, T. Kumakiri, M. Ikenaga and C. Kagaya: Mater. Trans. 54 (2013) 732-737.

17) N. Vidakis, A. Antoniadis and N. Bilalis: J. Mater. Process. Technol. 143-144 (2003) 481-485.

18) M. Umeno, M. Noda, H. Uchida and H. Takeuchi: Diamond Related Materials 17 (2008) 684-687.

19) P.C.S. Silva, M.A.R. Ramos, E.J. Corat and V.J.T. Airoldi: Mater. Res. 19 (2016) 882-888.

20) A.C. Ferrari and J. Robertson: Phys. Rev. B 61 (2000) 14095-14107.

21) J. Robertson: Surf. Coat. Tech. 50 (1992) 185-203.

22) M.J. Paterson, K.G. Orrman-Rossiter, D.K. Sood and S.K. Bhargava: Diamond Related Materials 2 (1993) 1439-1444.

23) J.H. Wang, S. Zhang, H.L. Wang, K.E. Wong, Q.A. Zhou and Y.Z. Zhou: Thin Films. 517 (2009) 5202-5206. 